\title{
Experiência de Pesquisa no Ensino Médio: A Filosofia da Práxis e a Escola
}

\section{Patrícia Aurora Corrêa Mazoti}

[...] a educação tem a ver com o talvez de uma vida que nunca poderemos possuir, com o talvez de um tempo no qual nunca poderemos permanecer, com o talvez de uma palavra que não compreenderemos, com o talvez de um pensamento que nunca poderemos pensar, com o talvez de um homem que não será um de nós. Mas que, ao mesmo tempo, para que sua possibilidade surja, talvez, do interior do impossível, precisam de nossa vida, de nosso tempo, de nossas palavras, de nossos pensamentos e de nossa humanidade (LARROSA, 2001, p. 289).

\section{Resumo:}

O tema deste artigo busca compreender a experiência de estágio a partir da conjuntura contemporânea da educação brasileira e à luz da filosofia da práxis. O objetivo é contribuir para a valorização da escola no processo de formação omnilateral da/o estudante, enfatizando o papel da filosofia no sentido de ampliar a formação aos âmbitos da autonomia intelectual, da sensibilidade estética e da formação ética. Desta forma, consideramos importante realizar o relato de experiência da sequência didática que partiu do interesse das/os estudantes que acompanhamos. Para tanto, aplicamos um questionário para 22 alunas/os que cursam a série do $2^{\circ}$ ano do ensino médio da Escola Estadual de São Paulo, da cidade de Marília. Ao realizar um vínculo entre a escola e as experiências particulares das/os estudantes, tornou-se possível a produção de um diálogo entre o

${ }^{1}$ Graduação em Filosofia (Licenciatura) pela Universidade Estadual Paulista Júlio de Mesquita Filho, Brasil(2015). Mestranda da Universidade Estadual Paulista Júlio de Mesquita Filho, Brasil - E-mail: correap07@gmail.com

Revista Digital de Ensino de Filosofia - Santa Maria - vol.2., n.1 - jan./jun.. 2016. 
conhecimento escolar e a vida das/os alunas/os, possibilitando, assim, que o conhecimento escolar tivesse mais relevância na existência prática das/os estudantes.

Palavras Chave: Senso comum e filosofia da práxis. Formação omnilateral. Experiência.

\title{
Research Experience in Secondary Education: The Praxis Philosophy and School
}

\begin{abstract}
:
The theme of this paper emerges from the search for understanding the internship experience from the contemporary situation of Brazilian education in the light of the philosophy of praxis. The goal is to contribute to the school's appreciation in the omnilateral student training process, emphasizing the role of philosophy in order to expand the training to areas of intellectual autonomy, aesthetic sensibility and ethics training. Therefore, we consider important to conduct interviews with students supervised. We applied the questionnaire to 22 high school students who attend the series $2^{\circ}$ year of high school in a state school in São Paulo, the city of Marilia. When performing a link between the school and the particular experiences of students, it became possible to produce a dialogue between school knowledge and the students' lives, enabling thus that school knowledge had more relevance in practical existence of the students.
\end{abstract}

Keywords: Common sense and philosophy of praxis. Omnilateral training. Experience.

\section{Introdução}

O presente trabalho emerge das reflexões sobre a nossa experiência no estágio e da conjuntura contemporânea da educação brasileira. A base encontrase no projeto "Senso comum e filosofia no ensino médio: perspectivas da filosofia da práxis" que desenvolvemos na iniciação científica e tem sua motivação no 
problema da especificidade da filosofia no processo de formação da/o estudante do ensino básico.

Utilizamos como metodologia textos teóricos, além da análise e levantamento de materiais junto as/aos estudantes que nos permitam pensar suas vivências e conhecimento do "senso comum" conjuntamente com a filosofia. Para tanto, aplicamos um questionário para 22 alunas/os que cursam a série do $2^{\circ}$ ano do ensino médio de uma Escola Estadual de São Paulo, localizada na cidade de Marília. A partir destes dados, realizamos uma sequência didática e um plano de aula cujos pressupostos buscaram dialogar com as experiências particulares das/os estudantes numa tentativa de tornar o conhecimento escolar mais relevante para a existência prática das/os mesmos.

O contato permanente com a escola, assim como a observação das contradições que a permeiam, possibilita que a Universidade venha a ser espaço de reflexão teórica e de propostas que, nascidas da prática, a torna um instrumento de emancipação humana e social. A hipótese levantada é constituída pela seguinte proposta: ao realizar um vínculo entre a escola e as experiências particulares das/os estudantes produziremos um diálogo entre o conhecimento escolar e a vida das/os alunas/os.

Assim, buscamos, através deste trabalho, a realização de um relato de experiência que contribua com uma educação omnilateral, que forneça um aparato intelectual para a/o estudante e, que assim, a/o forme nos aspectos da autonomia intelectual, da sensibilidade estética e da formação ética. Tomamos partido da ideia de que o ensino possui como intuito a formação de seres que refletem não apenas sobre questões que já foram postas por inúmeros pensadores, mas que devem ser levados para uma reflexão sobre si, sobre suas experiências, sua família, sua conduta. Uma formação crítica que forneça várias possibilidades teóricas e instrumentos para a criação de suas teorias, sejam de caráter científico ou subjetivo. Nas palavras de Gramsci:

É preciso destruir o preconceito, muito difundido, de que a filosofia é algo muito difícil pelo fato de ser a atividade intelectual própria de uma determinada categoria de cientistas especializados ou de Revista Digital de Ensino de Filosofia - Santa Maria - vol.2., n.1 - jan./jun.. 2016. 
filósofos profissionais sistemáticos. É preciso, portanto, demonstrar preliminarmente que todos os homens são "filósofos", definindo os limites e as características desta "filosofia espontânea", peculiar a "todo mundo", isto é, a filosofia que está contida: 1) na própria linguagem, que é um conjunto de noções e de conceitos determinados e não, simplesmente, de palavras gramaticalmente vazias de conteúdos; 2) no senso comum e no bom senso; 3) na religião popular e, consequentemente, em todo o sistema de crenças, superstições, opiniões, modos de ver e de agir que se manifestam naquilo que geralmente se conhece por "folclore" (2004, p. 93).

\section{Reflexões sobre os problemas da educação brasileira}

Atualmente, no Brasil, no contexto da crise política e econômica, o ensino, aprendizagem e a educação têm ganhado cada vez mais força e conformado debates calorosos sobre o tema. Isso não quer dizer, porém, que a ideia de Estado Regulador no Brasil só tenha chegado agora. Na verdade, dada as especificidades brasileiras, a concepção de Estado Desenvolvimentista - comum à países periféricos em função de sua "modernização" tardia - persistiu e ainda angaria vários defensores. Em seu trabalho, Cunha (2007) evidencia a crescente privatização do ensino brasileiro verificado desde a Ditadura Militar brasileira, processo esse que fora intensificado substancialmente a partir do governo FHC.

A abertura do ensino - fundamental, médio e superior - à iniciativa privada, segundo o autor, tem se dado de inúmeras formas, seja através do apoio governamental para os empresários do ensino - por meio de "imunidade fiscal, garantia de pagamento das mensalidades pelos alunos, mediante bolsas de estudo distribuídas pelo poder público" - "e até mesmo a inibição de iniciativas governamentais de criação e/ou ampliação de escolas" (p. 812).

Esse processo fica claro quando adentramos na discussão da chamada "reorganização escolar" proposta pela Secretaria da Educação do Estado de São Paulo. Os dados apresentados como justificativa para a implementação de mudanças apontam para uma diminuição crescente do número de alunos da rede

Revista Digital de Ensino de Filosofia - Santa Maria - vol.2., n.1 - jan./jun.. 2016. 
pública, o que, para os defensores dessa proposta, significa um percentual de escolas e salas de aula "ociosas" (em um contexto em que cada vez mais professores se queixam de salas superlotadas, falta de laboratórios, salas de leitura, necessidade de ampliação de bibliotecas - uma contradição notável dos discursos). O problema, na verdade, não está nos dados, que acreditamos serem reais, mas sim na falta de problematização e discussão na amostragem dos mesmos, pois em nenhum momento se é mencionado o fomento público às instituições de ensino privadas, fato esse que corrobora diretamente na diminuição da demanda do alunado para as escolas públicas.

Outra questão sobre esse tema inclina-se na justificativa pedagógica de que a separação dos ciclos - Fundamental II e Ensino Médio - produz uma melhoria significativa na aprendizagem dos alunos. Ao refletir sobre o processo que ocorreu nos anos de 1990 - a separação do Fundamental I - podemos perceber que a argumentação é falaciosa, já que, em longo prazo, o que se percebe é a pretensão de municipalizar todo o Ensino Fundamental, ônus esses que, provavelmente, as receitas das prefeituras municipais não terão como arcar, desencadeando, por sua vez, a abertura do ensino à outras iniciativas, nãogovernamentais e privadas. Arelaro (1999) considera que "fruto das iniciativas do governo [federal e estadual], visando adequar o Estado aos novos modelos de racionalidade" e, assim, contribuem para o "enxugamento do aparato estatal" (p. 65). Esse processo já está bem adiantado no Estado de Goiás, no qual os constantes debates sobre o ensino público estadual tem se inclinado à delegação da gestão do mesmo as chamadas Organizações Sociais (OS). Em outras palavras, o que estamos vivenciando é a "terceirização" das responsabilidades sociais do Estado para outras entidades (semelhante ao que aconteceu com vários segmentos 'profissionais).

Por fim, a crescente tecnicização do ensino que temos verificado no âmbito das políticas públicas estaduais (FATEC e Centro Paula Souza, por exemplo) e também federal (a expansão deliberada dos Institutos Federais) colaboram por sustentar o modelo de sociedade que os poderes públicos pretendem alcançar: uma "pátria" trabalhadora, que não pensa, tampouco reflete sobre si mesma. A 
emancipação dos indivíduos pelo saber, a formação do cidadão crítico e a contribuição do ensino para a prática da cidadania não parecem ter mais sentido no sistema educacional brasileiro, ainda mais se pensarmos as discussões estapafúrdias de projetos de leis que veem gênero como ideologia ou querem penalizar educadores se os mesmos tratarem de temáticas consideradas impróprias por essa onda neoconservadora. Dessa forma, a educação pública brasileira corre perigo e sua defesa deve ser feita a partir de reflexões que evidenciem a lógica e ética mercadológica por trás das ações políticas em voga.

\section{Filosofia da Práxis no Ensino Médio}

Compreende-se que, diante da conjuntura contemporânea da educação brasileira, a nossa empreitada com o ensino da filosofia possui o intuito de emancipação reflexiva do sujeito que proporcionará um aparato intelectivo para as/os estudantes e, assim, as/os formem nos aspectos do conhecimento intelectual, estético e ético. O investimento na articulação da atividade filosófica pelas/os estudantes através do incentivo à análise de seus sensos comuns em relação com as considerações proporcionadas pela filosofia e, por conseguinte, o encadeamento do exercício de fundação de argumentos, por vezes, se mostraravam inconsistentes e contraditórios. Quando alcançado este objetivo satisfatoriamente, podemos educar estudantes que se reconheçam como sujeitos de suas histórias formativas. Buscamos a realização de uma educação omnilateral que forneça o pleno desenvolvimento ao ser humano, procurando formá-lo em toda a sua amplitude. Utilizamos, como base de uma possibilidade de reflexão sobre o ensino, as colocações realizadas por Marx durante o I Congresso da Associação Internacional dos Trabalhadores. Ele expõe a forma que deveria ser a educação humana e os caminhos que esta deveria tomar para que não se inclinasse apenas no utilitarismo, aponta:

Por educação, entendemos três coisas:

1) Educação intelectual.

2) Educação corporal, tal como a que se consegue com exercícios de ginástica e militares.

Revista Digital de Ensino de Filosofia - Santa Maria - vol.2., n.1 - jan./jun.. 2016. 
3) Educação tecnológica, que recolhe os princípios gerais e de caráter científico de todo o processo de produção e, ao mesmo tempo, inicia as crianças e adolescentes no manejo de ferramentas elementares dos diversos ramos industriais (MARX; ENGELS, 2004, p. 68).

A disciplina de filosofia, portanto, deve ser trabalhada de forma crítica. Para isso, ela deve ser abordada a partir dos problemas filosóficos. Nesse contexto, as teorias filosóficas funcionam como possíveis respostas e, desse modo, se tornam passíveis de avaliação e de serem examinadas analiticamente, o que, por sua vez, estimularia o pensamento crítico e a autonomia da/o estudante. Se a teoria não for avaliada e examinada, então, o estudante não estará adquirindo os benefícios que a filosofia é capaz de fornecer. Isso porque a/o estudante estará meramente decorando o funcionamento interno de certo sistema filosófico e não desenvolvendo as habilidades de avaliação e exame analítico e, tampouco, estará desenvolvendo sua criticidade e autonomia, já que:

A filosofia que se vê a si mesma como instrumento teórico da práxis é teoria, e como tal não transforma real e efetivamente por si própria. Interpretar não é transformar. Mas- como diz Marx na tese Xl- trata-se é de transformar, daí que a teoria tenha de ser arrancada de seu estado meramente teórico e, pelas mediações adequadas, buscar realizá-la. Porém, esse segundo aspecto, vital quando não se aceita - mundo como é e se tenta transformá-lo, longe de abolir o conteúdo teórico da filosofia, ou de reduzi-lo a um ingrediente meramente ideológico, o pressupõe necessariamente - no nível da ciência- como condição iniludível para guiar a ação. Assim, a atividade filosófica enquanto tal não é práxis. E não é tampouco filosofia da práxis ou teoria da atividade prática do homem em suas relações com a natureza e com outros homens (SÁNCHEZ VÁZQUEZ, 2007, p. 236).

As/os alunas/os estão acostumados a lidar com estudos sobre fatos concretos. Também, há certo problema com relação ao aspecto conceitual da 
atividade filosófica, em contraposição às ciências empíricas. É importante considerar, além disso, que a/o aluno pode simplesmente não gostar do assunto. Tal circunstância é uma possível explicação do desinteresse dos estudantes com relação à disciplina ou, além disso, pode explicar a frustração daquelas/es que possuem outras expectativas com relação à filosofia.

Em resumo, a filosofia deve ser ensinada através de uma maneira particular de abordagem dos problemas filosóficos "por intermédio da experiência filosófica educamos o outro para ser outro. A educação filosófica deve gerar a manutenção da pluralidade, do diverso, do singular. Uma ação pedagógica não deve promover a reprodução do mesmo" (ASPIS, 2004, p. 313). Nessa situação, as teorias são avaliadas e confrontadas frente aos problemas filosóficos o que exige competências analíticas, interpretativas e avaliativas da/o estudante e, por conseguinte, sua criticidade e autonomia são desenvolvidas de uma maneira peculiar proporcionada pela filosofia. Essas pontuações foram suscitadas por Gramsci:

No ensino da filosofia dedicado não a informar historicamente 0 discente sobre o desenvolvimento da filosofia passada, mas para formá-lo culturalmente, para ajudá-lo a elaborar criticamente o próprio pensamento e assim participar de uma comunidade ideológica e cultural, é necessário partir do que o discente já conhece, da sua experiência filosófica (após tê-lo demonstrado que ele tem uma tal experiência, que ele é um "filósofo" sem o saber). E, já que se pressupõe uma certa média intelectual e cultural nos discentes, que provavelmente não tiveram ainda senão informações soltas e fragmentárias, carecendo de toda preparação metodológica e crítica, não é possível deixar de partir do "senso comum", em primeiro lugar, da religião, secundariamente, e — só em uma terceira etapa - dos sistemas filosóficos elaborados pelos grupos intelectuais tradicionais (1978, p. 148).

A questão que se coloca então é: podemos aplicar essa proposta em sala de aula? Bom, deve-se trabalhar com os problemas filosóficos explicando-os e 
confrontando as teorias que visam respondê-los. Porém, como explicar e apresentar esses elementos de uma maneira suficientemente para que desperte o interesse das/os alunas/os?

Reforçamos a necessidade da filosofia se fazer presente em ações, e não apenas permanecer no universo intelectual. Contudo, essa afirmação não pode ser analisada como uma desqualificação da filosofia ou dos escritos filosóficos, mas como uma tentativa de transcender a tradição metafísica e, os problemas colocados por esta. Para darmos um passo adiante: devemos refletir criticamente sobre a nossa sociedade e, assim, partirmos das questões teóricas para uma junção com a reflexão de problemas que afligem as/os nossas/os estudantes. Assim, consideramos que:

aprender a filosofar só pode ser feito estabelecendo um diálogo crítico com a filosofia. Do que resulta que se aprende a filosofar aprendendo filosofia de um modo crítico, quer dizer, que 0 desenvolvimento dos talentos filosóficos de cada um se realiza pondo-os à prova na atividade de compreender e criticar com a maior seriedade a filosofia do passado ou do presente [...] Kant não é um formalista que preconiza que se deve aprender um método no vazio ou uma forma sem conteúdo; tampouco se segue que Kant tivesse avalizado a idéia de que é necessário lançar-se a filosofar sem mais nem muito menos a idéia de que os estudantes deveriam ser impulsionados a 'pensar por si mesmos', sem necessidade de se esfor- çar na compreensão crítica da filosofia, de seus conceitos, de seus problemas, de suas teorias etc (OBIOLS, 2002, p. 77).

O papel formativo da escola deve ser destacado na discussão acerca de saberes que são considerados subalternos, ou seja, aqueles que estão à margem da elucubração do conhecimento hegemônico (europeizado) que recebemos como herança. Heller (1970) considera que vida cotidiana, portanto, possui uma história própria que não se antagoniza com a totalidade. É constituída pelo conjunto de atividades que fazem parte do dia a dia da maioria dos seres humanos. Este espaço concreto, particular, se apresenta a partir do modo como o 
homem se constrói por meio da apropriação do mundo e uma possibilidade de estruturação da consciência e um caminho para a desalienação. Deste ponto de análise, emerge a figura do indivíduo que é sempre, e simultaneamente, particular e genérico.

A teoria de Heller (1970) considera a preocupação constante com a valorização daquilo que tradicionalmente é visto como inconsistente ou insignificante do ponto de vista da elaboração do conhecimento: o senso comum. Compreende que o mesmo está presente, em maior ou menor nível, na cotidianidade de todo indivíduo, como forma de conhecimento fundamentada sobre a base da probabilidade e da possibilidade. O dia a dia, em geral, está repleto de situações que exigem dos seres humanos atitudes espontâneas, portanto, desprovidas de reflexões rigorosas e teóricas. No entanto, por meio dessa espontaneidade, os indivíduos conseguem se orientar e responder satisfatoriamente às suas necessidades.

\section{Sequência didática e relato de experiência}

As reflexões e análises aqui descritas são resultados da nossa atuação na atividade de estágio realizada no Ensino Médio em uma Escola Estadual na cidade de Marília - SP. O estágio fora realizado em junho de 2015. Para tanto, pretendemos aqui fazer uma análise desta experiência. Pesquisamos o ensino de filosofia durante a graduação e - por se tratar da realidade que abordamos teoricamente como bolsista Pibic - procuramos relacionar e tencionar a pesquisa teórica e a realidade escolar. Aplicamos o questionário base de nosso trabalho "Senso comum e filosofia no ensino médio: perspectivas da filosofia da práxis" para 22 alunas/os que cursam a série do $2^{\circ}$ ano do ensino médio. Com o intuito de compreender a concepção de mundo das/dos estudantes, apresentaremos uma sequência didática baseado nestes dados, ou seja, nas escolhas das/os alunos.

Desta forma, a hipótese é a de que as propostas escolares, se adequadamente relacionadas com o contexto histórico-social vivido, podem tornar-se significativas a professores, estudantes e contribuir para que se 
reconheçam como sujeitos da sua história formativa. Assim, o conhecimento escolar seria mais relevante na existência prática das/os estudantes, pois:

As inquietações dos jovens pela busca de compreensão, de significado e valor da realidade são genuínas e precisam de respeito para serem de alguma forma apaziguadas pelas respostas complexas encontradas, por mais provisórias que sejam. Portanto, tudo deve partir das questões dos alunos. Não há razão para pensarmos ensino de filosofia se não for da filosofia viva e vivificante que pode ser construída a partir das aflições tão humanas, do estranhamento e incômodo com a ordem vigente da vida como ela se nos aparece. A filosofia surge como tentativa de elaboração de saídas para problemas concretos, por meio da criação de seus conceitos. As questões filosóficas são universais, são humanas (ASPIS, 2004, p. 309-310).

O questionário pré-elaborado² foi constituído de nove questões de múltipla escolha em que se procurou efetuar uma aproximação com o universo das/os jovens e refletir sobre suas concepções de mundo. A primeira questão buscava a compreensão da importância da matéria "Filosofia" que faz parte da formação da/o aluna/o a partir do ensino médio. A segunda questão possui uma indagação de cunho pessoal sobre o significado da utilidade do conhecimento recebido através dos vários anos de estudo que as/os alunas/os brasileiros cursam. A terceira questão abordou as pretensões dos estudantes após o término do ensino médio. A quarta questão foi elaborada para estimar os interesses por áreas das/os alunas/os do ensino médio. Nesta questão, a/o estudante deveria designar o modo de produção de conhecimento que julga como de maior importância para a sua

\footnotetext{
2 As questões foram baseadas no levantamento realizado pelas seguintes pesquisas SILVA, Vandeí Pinto da.; SANTOS, Genivaldo de Souza ; MARINHO, F. G. R. . Senso comum e filosofia no ensino médio: perspectivas. In: Sheila Zambello de Pinho; Maria de Lourdes Spazziani; Sueli Guadelupe de Lima Mendonça; Elisabete Aparecida Andrello Rubo; Dalva Maria de Oliveira Villareal. (Org.). Ser e tornar-se professor: práticas educativas no contexto escolar. led.São Paulo: Cultura Acadêmica: UNESP, Prograd, 2012, v. , p. 381-389.
}

Revista Digital de Ensino de Filosofia - Santa Maria - vol.2., n.1 - jan./jun.. 2016. 
tomada de ações. A sexta questão tratou sobre a instituição escolar. Consideramos a obtenção de dados, ao elaborar a sétima questão, sobre a afinidade intelectual das/os alunas/os com modelos de produção de conhecimento. A penúltima questão versou sobre a análise da compreensão da função da filosofia pelo estudante. A última questão, de cunho expressamente pessoal, indagou a/o aluna/o sobre os problemas do seu cotidiano que apreciaria como tema de uma discussão filosófica. "Pensamento, ação e o futuro" foram os temas escolhidos por oito das/dos alunas/os. As questões filosóficas "ética, verdade, certo e errado" foram as escolhas de um estudante. Os temas da "religião, Deus e mitos" foram a opção de três estudantes. "Trabalho e lazer" é a discussão proposta por três alunas/os. Nenhum estudante escolheu a opção "outros".

A proposta de sequência didática abordou a questão que mais recebeu escolhas pelas/os alunas/os quando responderam a última questão do questionário, a saber: "Sobre quais problemas do seu cotidiano você gostaria de discutir filosoficamente?". A proposta apresentada neste trabalho, abordará a resposta escolhida pela maioria que foi "Pensamento, ação e o futuro".

Consideramos que no âmbito do estudo da filosofia, devemos buscar o investimento na articulação da filosofia pelas/os estudantes que serão incentivados a refletir sobre seus valores, posição política, ideológica e religiosa. Isto posto, foram apresentados ao público-alvo deste trabalho alguns textos de Filosofia Clássica, Filosofia Contemporânea, Literatura e História Cultural que as/os convidavam a uma reflexão em um diálogo constante com o mundo vivido e percebido por elas/es. A partir destes fragmentos pretendeu-se iniciar e sensibilizar as/os estudantes para um debate, explorando, a partir do conhecimento prévio dos alunos, o que elas/es consideram ser a sua visão da temática, já que:

Filosofia não pode ser ensinada no sentido de ser transmitida, pela mesma razão pela qual ela não pode ser escrita, como diria Platão no Fedro (274c), porque ela depende de uma atitude tão vivencial e ativa do sujeito que aquele que se situa como suposto transmissor da filosofia se coloca num não-lugar filosófico (GALLO; KOHAN, 2000, p. 182).

Revista Digital de Ensino de Filosofia - Santa Maria - vol.2., n.1 - jan./jun.. 2016. 
Em seguida, fizemos a exposição oral da temática. Aqui, foram explorados os motivos que levaram à elaboração do elevado número de conceitos que a abordagem de determinado texto implicava, introduzindo algumas atividades de conceptualização que permitiam superar a ambiguidade semântica de alguns conceitos. Aproximação linguística aos conceitos de "ação" e de "agente" mediante a análise dos seus vários significados correntes e da determinação dos que e só dos que convém aqui. Aproximação predicativa ao conceito de "ato humano" através da explicitação dos atributos que fazem de uma ação um ato verdadeiramente humano. Análise de textos com posições diversificadas sobre determinismo e liberdade na ação, visando à formulação de problemas. A leitura e análise de textos escritos que seriam feitas através de uma aula expositiva e dialogada foi a metodologia escolhida para essa experiência docente. Baseamonos nas OCN/Filosofia que consideram:

[...] a metodologia mais utilizada nas aulas de filosofia é, de longe, a aula expositiva, muitas vezes com o apoio do debate ou de trabalhos em grupo [...] [mas que] Em função de alguns elementos preponderantes, como o uso do manual e a aula expositiva, é possível dizer que a metodologia mais empregada no ensino de Filosofia destoa da concepção de ensino de Filosofia que se pretende (BRASIL, 2008, p. 36).

A experiência, aqui descrita, foi composta e iniciada pela leitura de um fragmento de textos filosóficos. Aristóteles considera que é livre aquele que tem em si mesmo o princípio para agir ou não agir, isto é, aquele que é causa interna de sua ação ou da decisão de não agir. Conforme o filósofo:

Que espécie de ações se devem, pois, chamar forçadas? Respondemos que, sem ressalvas de qualquer espécie, as ações são forçadas quando a causa se encontra nas circunstâncias exteriores e o agente em nada contribui. Quanto às coisas que em si mesmas são involuntárias, mas, no momento atual e devido às vantagens que 
trazem consigo, merecem preferência, e cujo princípio motor se encontra no agente, essas são, como dissemos, involuntárias em si mesmas, porém, no momento atual e em troca dessas vantagens, voluntárias. E têm mais semelhança com as voluntárias, pois que as ações sucedem nos casos particulares e, nestes, são praticadas voluntariamente. Que espécies de coisas devem ser preferidas, e em troca de quê? Não é fácil determiná-lo, pois existem muitas diferenças entre um caso particular e outro. (ARISTÓTELES, 1991:47)

As/os alunos tiveram um tempo para se posicionarem e expressarem oralmente sobre o assunto, que foi baseado em suas próprias experiências. Logo na primeira leitura, verificou-se a dificuldade de entendimento do enunciado da discussão efetuada por Aristóteles. Após uma explicação sobre a articulação dos argumentos, as/os alunas/os começaram a discutir os princípios do autor, mas poucos participaram.

Em seguida, foi apresentado o Fragmento de Texto literário:

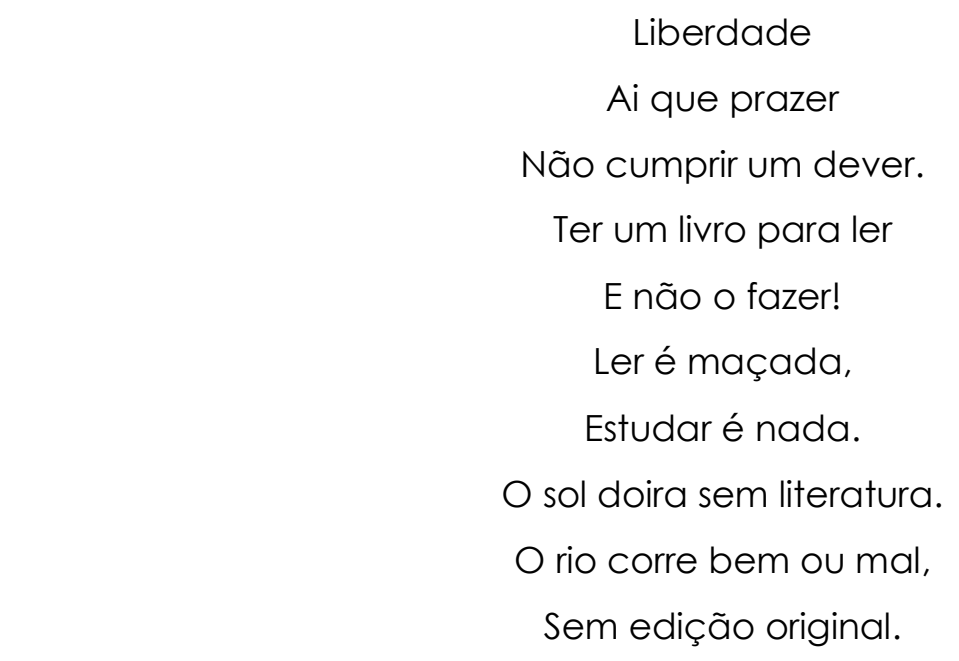

E a brisa, essa, de tão naturalmente matinal

Como tem tempo, não tem pressa...

Livros são papéis pintados com tinta.

Estudar é uma coisa em que está indistinta

A distinção entre nada e coisa nenhuma.

Revista Digital de Ensino de Filosofia - Santa Maria - vol.2., n.1 - jan./jun.. 2016. 
Quanto melhor é quando há bruma.

Esperar por D. Sebastião,

Quer venha ou não!

Grande é a poesia, a bondade e as danças...

Mas o melhor do mundo são as crianças,

Flores, música, o luar, e o sol que peca

Só quando, em vez de criar, seca.

E mais do que isto

É Jesus Cristo,

Que não sabia nada de finanças,

Nem consta que tivesse biblioteca...

(PESSOA, 1937, n. 526)

Não houve demonstração de dificuldade em compreender a ligação temática ente os dois fragmentos de textos. A discussão suscitou, diferente da primeira, muitos posicionamentos em relação aos conceitos. Diversos alunas/os concordaram com a "Liberdade" proposta por Fernando Pessoa e associaram as ideias do autor com suas próprias vivências. Uma aluna, que não havia se manifestado na discussão sobre o fragmento de Aristóteles, sentiu-se satisfeita com a crítica de Pessoa em relação à educação. Pediu-se para que esclarecesse o motivo e esse foi enunciado da seguinte forma: "Jesus não estudou segundo uma passagem bíblica" e continuou "eu não gosto de estudar e estou aqui obrigada pelos meus pais". Ela tomou como ponto de partida suas convicções religiosas e suas experiências pessoais. Entretanto, a leitura dos fragmentos forneceu um apoio teórico que the permitiu refletir sobre sua vivência e expressá-la de forma organizada, defendendo sua perspectiva: "Essa é uma imposição, como o Aristóteles disse é uma ação forçada".

Logo após, tratamos do fragmento de Filosofia Contemporânea que expõe a concepção de Sartre a liberdade é a escolha incondicional que o próprio homem faz de seu ser e de seu mundo. Este autor afirma que estamos condenados à liberdade, pois:

Revista Digital de Ensino de Filosofia - Santa Maria - vol.2., n.1 - jan./jun.. 2016. 
Com efeito, sou um existente que aprende sua liberdade através de seus atos; mas sou também um existente cuja existência individual e única temporaliza-se como liberdade [...] Assim, minha liberdade está perpetuamente em questão em meu ser; não se trata de uma qualidade sobreposta ou uma propriedade de minha natureza; é bem precisamente a textura de meu ser (SARTRE, 1998, p. 542/543).

Seguidamente apresentamos o fragmento da história cultural:

Um provérbio popular, com base na Revolução Francesa e na Declaração dos Direitos do Homem e do Cidadão diz: "A minha liberdade termina onde começa a do outro".

A interação entre as/os alunas/os foi mais intensa. As reflexões delas/es mostraram que o texto filosófico e o provérbio levaram as considerações sobre as suas convivências dentro de sala de aula - ponderaram os momentos de conversas e exacerbação de ruídos que atrapalham aquelas/es que desejam estudar - e com outros aspectos cotidianos de suas existências. Esses aspectos foram até vinculados com direitos civis, por exemplo, vários meninos citaram a obrigatoriedade do serviço militar e disseram: "por que preciso fazer Tiro de Guerra3, por que tenho que pisar em quartéis?". Essa dinâmica de interagir o conhecimento proveniente de seu dia a dia com questões de cunho teórico permitiu uma argumentação que moldou teses e posições justificadas.

A base para a concepção de competências que buscamos alcançar encontra-se na análise de Murcho (2008). O autor considera que no ensino de filosofia é preciso ensinar a ler os textos filosóficos ativa e filosoficamente. A formação filosófica deve munir as/os estudantes com instrumentos para realizarem uma leitura realmente de cunho filosófico, para tanto "Os textos são lidos ativamente quando o estudante se pergunta a cada passo se o filósofo tem razão, se a teoria é plausível, se os argumentos apresentados são cogentes, se as definições são aceitáveis, etc" (MURCHO, 2008, p. 93).

\footnotetext{
${ }^{3}$ No Brasil, aos dezoito anos, as pessoas do sexo masculino devem, obrigatoriamente, se apresentar para o alistamento no serviço militar.
}

Revista Digital de Ensino de Filosofia - Santa Maria - vol.2., n.1 - jan./jun.. 2016. 
Murcho expõe as articulações filosóficas através de conceitos básicos como a teoria e a argumentação. A teoria consiste na construção de respostas para os problemas colocados para a filosofia. Ele esclarece que as teorias podem ser chamadas de teses, perspectivas ou de filosofias. Os problemas filosóficos podem ser considerados ilusórios, não plausíveis, mas diferente das ficções literárias, são indagações consideradas importantes para o desenvolvimento do ser humano por aquelas/es que buscam a sua resolução.

Os argumentos são os meios para formularmos teses. Eles possuem um peso de importância para a filosofia, pois não existem teorias consensuais. Logo, a articulação dos argumentos se mostra como o núcleo para a construção de perspectivas e para a defesa desta. A respeito do ensino de filosofia, o autor considera que "é importante saber que razões têm cada um dos filósofos para pensar que a sua teoria é verdadeira; se não o fizermos, a/o estudante fica com a noção errada de que a filosofia é apenas uma rapsódia de teorias diferentes umas das outras" (MURCHO, 2008, p. 90). Pensando nesses aspectos, consideramos importantes o desenvolvimento das seguintes competências pelas/os alunas/os: Expressar por escrito e oralmente questionamentos sobre o processo de conhecimento; Reflexão crítica; Problematizar valores e Relacionar informações representadas de diferentes formas.

Através desta experiência não pretendemos que as/os estudantes - ao se aproximar pela primeira vez destes textos que abordam a história da filosofia, literários e/ou provérbio popular - apreendam todas as suas extensões e significados. Pelo contrário, o que se pretende é uma sensibilização com a temática e com o exercício de pensar através de conceitos que forneceram os elementos para a discussão que partiram das suas concepções e adentraram as reflexões de cunho filosófico. Desta forma, essa experiência não pretende ser um molde para o ensino de filosofia, pois consideramos que:

Não há manuais para as aulas de filosofia. Não é possível fazer um manual para algo que ainda não veio a ser. Há sim, no mercado editorial, livros para o ensino de filosofia. Mas estes não podem servir para nada além de, no máximo, trazer elementos para a criação 
própria e fresca de cada professor para cada aula. O que equivale dizer que o professor deve ser o criador de instrumentos e estratégias. A cada diferente grupo, a cada diferente ano ou escola, é necessário inventar os personagens coadjuvantes das nossas aulas. Alguns se prestam a ser repetidos, outros não. Assim o professorfilósofo é também um artesão. Ele vai confeccionar exercícios, vai selecionar textos, ele vai criar atividades e jogos. E assim, exercitando sua criatividade, será também modelo de criatividade (ASPIS, 2004, p. 316).

\section{Conclusões sobre o Ensino de Filosofia}

Partimos da proposta da busca de uma construção de novas formas de ensinar a filosofia, na qual, o filosofar é algo relacionado às mudanças subjetivas e deve ser ligado à realidade enfrentada pelas/os alunas/os diariamente, na busca, também, de trabalhar o pré-conceito referente à filosofia que a coloca como um conhecimento abstrato e realizável por poucos. Consideramos, assim, o diferencial desta disciplina para a formação da/o aluna/o que cursa o ensino médio e, além disso, a importância da relação entre a/o professor/a e as/os estudantes e a necessidade de torná-la recíproca e mediadora do processo de elaboração educativo e da descolonização de olhares.

O contato com o ensino médio - e as contradições que o permeiam - deve possibilitar que as/os professoras/es venham a formar um espaço de reflexão teórica e de elaborações de propostas que, referenciadas nas micro diferenças das/os estudantes, a torne um instrumento que engendra o ser humano e o constitui para atuar reflexivamente nas suas vivências. Cabe à escola atuar na educação e, 
ao mesmo tempo, problematizá-la com o intuito de se fazer ligada a sociedade contemporânea.

Articulamos a sequência didática na busca de desenvolver uma educação que produza cidadãos críticos e com a visão de que o filosofar é algo relacionado à práxis. Consideramos que as aulas de filosofia são um:

lugar da experiência filosófica, têm como objetivo oferecer critérios filosóficos para o aluno julgar a realidade por meio da prática do questionamento filosófico e da construção de conceitos, por meio do exercício da criatividade e avaliação filosóficas (ASPIS, 2004, p. $310)$.

Desta forma, compreendemos a importância em realizar uma proposta didática que partisse do interesse das/os estudantes que acompanhamos e, por isso, selecionamos como parte da metodologia a aplicação do questionário. A sequência das aulas buscaram o desenvolvimento das seguintes habilidades: escrita, leitura e expressão oral na abordagem de temas filosóficos; a elaboração de hipóteses e questões a partir das leituras e debates realizados; a percepção sobre a presença da Filosofia no cotidiano e, por fim, a identificação das características da Filosofia como reflexão.

Delineamos algumas considerações na busca de elaborar uma experiência de ensino, mas constituindo-se apenas como uma possibilidade que ocorre através da articulação de uma necessidade de refletir sobre perspectivas da contribuição do ensino de filosofia para a formação das/os estudantes. O ato de ensinar se coloca como deveras complexo, pois ele é relativo a contextos mutáveis. Exemplo desta afirmação foi encontrado por nós ao realizar a etapa de observação e regência do estágio: às quartas-feiras observamos e regemos as 6 aulas de filosofia da sequência didática proposta para 3 diferentes salas do segundo ano do ensino médio. Percebemos que cada sala articulava a mesma situação de aprendizagem conforme o seu interesse e suas realidades diferenciadas. 
Diante deste contexto, o mais profícuo que a experiência do estágio pôde ofertar para a/o futura/o professor/a de filosofia vai para além de elucubrações teóricas sobre o ensino e/ou a filosofia da educação, pois compreendemos que a sua contribuição encontra-se na problematização da necessidade de buscar possibilidades frente aos desafios que a educação brasileira contemporânea sinaliza. Para aquelas/es preocupados em prover uma formação omnilateral da/o estudante, sem dúvida, essa inquietação a/o acompanhará por toda a sua carreira docente, uma vez que o objetivo deve sempre buscar uma formação educativa mais inclusiva, dinâmica e participativa, dialogando diretamente com a vida prática das/os estudantes. 


\section{Referências bibliográficas:}

ARELARO, L. R. G. A municipalização do ensino no Estado de São Paulo:

antecedentes históricos e tendências. In: OLIVEIRA, C. et al. (Org.). Municipalização do ensino no Brasil: algumas leituras. Belo Horizonte, MG: Autêntica, 1999. p. 61-89.

ARISTÓtELES. Ética a Nicômaco. 4. ed. São Paulo: Nova Cultural, 1991.

ASPIS, Renata Pereira. O professor de filosofia: o ensino de filosofia no ensino médio como experiência filosófica. Cadernos CEDES, Campinas, vol. 24, n. 64, p. 305- 320, set./dez. 2004.

BRASIL. Ministério da Educação. Secretaria de Educação Básica. Orientações Curriculares

Nacionais para o Ensino Médio. v. 3. Ciências Humanas e suas tecnologias. Brasília, DF, 2008.

CUNHA, L. A. Educ. Soc., Campinas, vol. 28, n. 100 - Especial, p. 809-829, out. 2007 809. Disponível em: <http://www.cedes.unicamp.br> Acessado em 22 de nov. de 2015.

GALLO, Sílvio; KOHAN, Walter Omar. Crítica de alguns lugares-comuns ao se pensar a Filosofia no ensino médio. In: (orgs.). Filosofia no Ensino Médio. Petrópolis: Vozes, 2000.

GRAMSCl, A. Cadernos do cárcere. Introdução ao estudo da filosofia. A filosofia de Benedetto Croce. 3. Ed. Rio de Janeiro: Civilização Brasileira, 2004, v. 1. 
. Concepção dialética da história. 2. ed. Rio de Janeiro: Civilização Brasileira, 1978.

HAYDT, R. C. C. Avaliação do processo ensino-aprendizagem. São Paulo: Ática, 1988.

HELLER, Ágnes. Estrutura da vida cotidiana. In: O cotidiano e a história. 4. Ed. São Paulo: Paz e Terra, 1970, p. 17 - 41.

LARROSA J. Dar a palavra. Notas para uma dialógica da transmissão. In: LARROSA, J.; SKLIAR, C. Habitantes de Babel: políticas e poéticas da diferença. Belo Horizonte: Autêntica, 2001.

MARX, K.; ENGELS, F. Textos sobre educação e ensino. 4. ed. São Paulo: Centauro, 2004.

MURCHO, D. A Natureza da Filosofia e o seu Ensino. $1^{a}$ Ed. Lisboa: Plátano, 2002.

OBIOLS G. Uma introdução ao ensino da filosofia. ljuí: Editora da UNIJUÍ, 2002.

PEIRCE, C. S. Semiótica e Filosofia. Tradução de Octanny Silveira da Mota e Leonidas Hegenberg, São Paulo, Cultrix, 1975.

SARTRE, J. P. O ser e o nada - ensaio de ontologia fenomenológica. Tradução: Paulo Perdigão. 6 ed. Rio de Janeiro: Vozes, 1998, p. 782. YAZBEK, A. C. Cadernos de ética e filosofia política 
SILVA, R. M. S. A importância da afetividade na relação professor aluno. In: KULLOK, Maísa Gomes Brandão (Org). Relação professor-aluno: contribuição à prática pedagogia. Maceió: EDUFAL, 2002. p: 51-74.

SÁSCHEZ VÁZQUEZ, A. Filosofia da práxis. São Paulo: Expressão popular, 2007. 